\title{
Protective Effect of Food Products Enriched with Unsaponifiable Matter from Palm Fatty Acid Distillate on the Aorta of Hypercholesterolemic Rats
}

\author{
Kgs Ahmadi ${ }^{1}$, Angela Wulansari ${ }^{2}$, Yunianta Subroto ${ }^{3}$, Teti Estiasih ${ }^{3 *}$ \\ ${ }^{1}$ Department of Agroindustry Technology, Faculty of Agriculture, Tribhuwana Tunggadewi University, Jl. Telaga Warna, Tlogomas, Malang, East Java, \\ Indonesia. ${ }^{2}$ Master Program of Agricultural Product Technology, Faculty of Agricultural Technology, Brawijaya University, Jl. Veteran, Malang, East Java, \\ Indonesia. ${ }^{3}$ Department of Food Science and Technology, Faculty of Agricultural Technology, Brawijaya University, Jl. Veteran, Malang, East Java, \\ Indonesia.
}

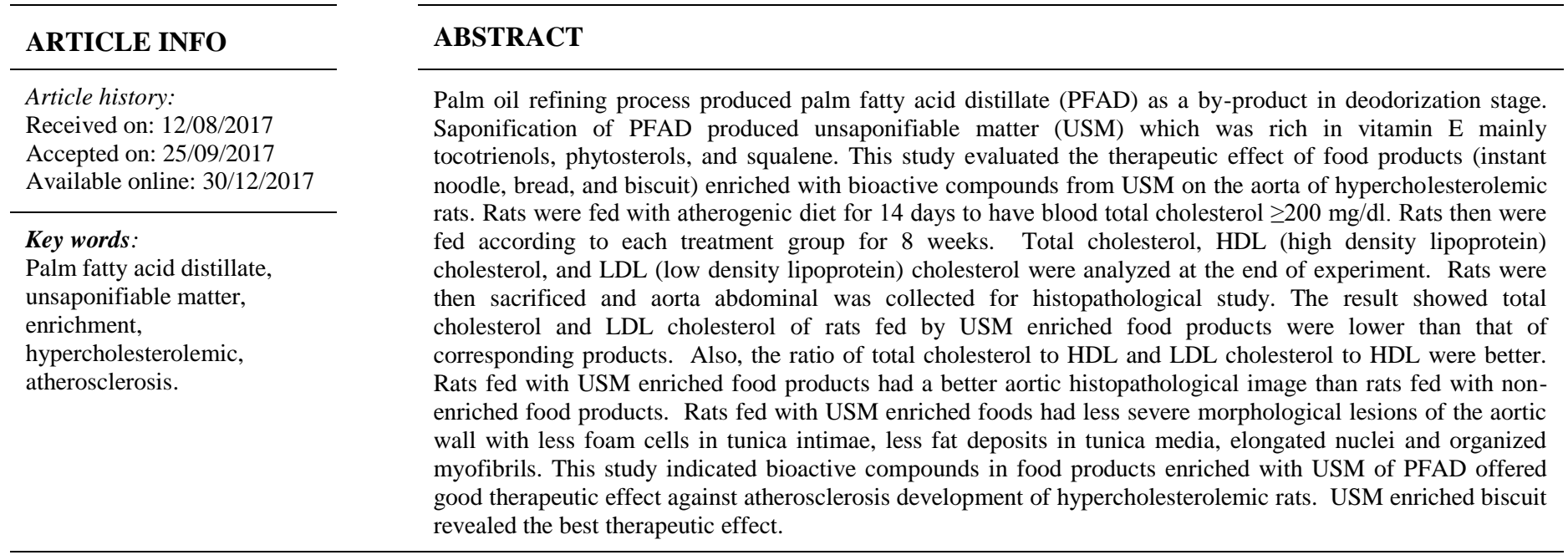

\section{INTRODUCTION}

Palm oil contains minor components such as carotenoids, vitamin E (tocopherol and tocotrienols), phytosterols, squalene, and phenolic compounds (Mukherjee and Mitra, 2009; Loganathan et al., 2009; Che et al., 2014). Deodorization stage on palm oil refining process is aimed to remove undesirable odor and free fatty acid, which also produces palm fatty acid distillate (PFAD) as a by-product. PFAD contains

\footnotetext{
* Corresponding Author

Email:teties@yahoo.co.id
}

free fatty acids and other minor components. Estiasih et al. (2013) reported PFAD was consisted of $85-90 \%$ fatty acids as main compound and bioactive compounds such as vitamin E (60-200 ppm), phytosterols (400-7500 ppm), and squalene (400-2800 ppm) as minor components. Separation of free fatty acids and bioactive compounds in PFAD can be occurred by saponification reaction. Fatty acids are hydrolyzed by the base to produce soap and other unsaponifiable components are dissolved in unsaponifiable fraction (Fernandes and Cabral, 2007). The study by Estiasih et al. (2014) showed unsaponifiable matters of PFAD was contained vitamin E 19600 ppm, phytosterols 5500 ppm, and squalene 323000 ppm. 
Research by Ahmadi et al. (2012) showed unsaponifiable matters of PFAD was contained $35000 \mathrm{ppm}$ vitamin $\mathrm{E}$ that consisted of $11844 \mathrm{ppm} \alpha$-tocopherol, $7441 \mathrm{ppm} \alpha$-tocotrienol, $2250.5 \mathrm{ppm} \delta$ tocotrienol, and $13464.5 \mathrm{ppm} \gamma$-tocotrienol.

Vitamin E, phytosterols, and squalene from USM of PFAD have a potential hypocholesterolemic effect. Estiasih et al. (2014) reported USM of PFAD decreased total cholesterol, triglyceride, LDL cholesterol, and increased HDL cholesterol level in hypercholesterolemic rats. Cholesterol, especially LDL cholesterol is a major risk factor for atherosclerosis. The presence of HDL cholesterol will affect the atherogenic degree of LDL cholesterol, therefore atherosclerosis could be prevented by improving lipid profiles (Tomkin and Owens, 2012).

Vitamin E in USM of PFAD is dominated by tocotrienols. Study by Qureshi et al. (2002) showed tocotrienols rich fraction supplementation decreased total cholesterol, LDL cholesterol, and triglyceride levels in human subjects with hypercholesterolemia. Oxidized LDL is the major cause of atherosclerosis. Vitamin $\mathrm{E}$ as antioxidant prevented oxidation of LDL cholesterol in in vitro study (Niki, 2011). A study in hyperlipidemic rats showed the group of rats treated with vitamin $\mathrm{E}$ had smaller atherosclerotic area than groups without vitamin $\mathrm{E}$ treatment (Hasty et al., 2007).

Phytosterols have the ability to compete with cholesterol during the formation of micelles in the intestine. Rats that given additional phytosterols in high-fat diet had lower total cholesterol, LDL cholesterol, and triglyceride levels (Awaisheh et al., 2013). Squalene, as an antioxidant, prevents free radical damage in cells (Buddhan et al., 2007). Squalene also reported to decrease cholesterol levels in plasma (Bombo et al., 2013), inhibit atherosclerosis formation, and decrease cholesterol levels in liver (Guillen et al., 2008).

Increasing number of chronic diseases such as cardiovascular disease, diabetes mellitus, and cancer, leads to increase promotion of enriched foods that have a health benefit in form of functional foods (Jew et al., 2009). Fortification of phytosterols have been done in some food products such as bread, cereals, and margarine which were decreased LDL cholesterol in human subject with hypercholesterolemia (Nestel et al., 2001). Fortification of vitamin E in milk (Hayes et al., 2001) and margarine (van het Hof et al., 1998) prevented LDL cholesterol oxidation and increased LDL cholesterol resistance to oxidation. The addition of high squalene containing food such as amaranth in pasta (Martinez et al., 2016), and rice bran oil in biscuit (Bhanger et al., 2008) increased squalene content of the food products and made them as a good source of antioxidant. USM of PFAD that contained phytosterols, squalene, and vitamin $\mathrm{E}$ is possible to use as ingredient for enriching foods to have hypocholesterolemic effect and aortic protection.

This study examined therapeutic effect of USM enriched instant noodle, bread, and biscuit against atherosclerosis development in hypercholesterolemic rats.

\section{MATERIALS AND METHOD Materials}

PFAD kindly obtained from PT Salim Ivonas Pratama, Surabaya, Indonesia. Reagents that used in this study were the technical grade reagents for preparation of USM and other chemical reagents for preparation of fresh specimens. Cholesterol kit (CHOD PAP) was used for lipid profile analysis. Other materials were instant noodle, bread, and biscuit ingredients, standard diet AIN-93M, and atherogenic diet ingredients (cholesterol, cholic acids, and tallow).

\section{Preparation of USM from PFAD}

Preparation and saponification of PFAD was according to the method of Estiasih et al. (2014).

\section{Preparation of USM enriched Food Products}

Instant noodle was made by mixing wheat flour, eggs, salt, water, and alkaline water until smooth. USM of PFAD as much as $1 \%$ of the dough $(\mathrm{w} / \mathrm{w})$ was added and mixed well. The dough was rested for $20 \mathrm{~min}$ then sheeted and slotted until had the strands of noodle. Noodle strands were steamed for $10 \mathrm{~min}$ at $100^{\circ} \mathrm{C}$ and fried in palm oil for $15 \mathrm{~s}$.

Bread was made by mixing dry ingredients such as wheat flour, sugar, milk powder and instant yeast. Egg yolks, margarine, and warm water were added to the dry ingredients and mixed. USM as much as $1 \%$ weight of dough $(\mathrm{w} / \mathrm{w})$ was added to the dough and mixed until smooth. The dough then rested for 30 $\mathrm{min}$. The dough was divided into $100 \mathrm{~g}$ and baked for $20 \mathrm{~min}$ at $180^{\circ} \mathrm{C}$.

Biscuit was prepared by mixing butter, margarine, egg yolk and sugar powder for 3 mins. Wheat flour, baking powder, salt and vanilla then added and mixed until smooth. USM as much as $1 \%$ of the dough $(\mathrm{w} / \mathrm{w})$ added and mixed well. The dough was sheeted and cut into $4 \times 4 \times 1 \mathrm{~cm}$, then baked for $15 \mathrm{~min}$ at $180^{\circ} \mathrm{C}$.

All food products were analyzed for bioactive compounds including vitamin E, phytosterols, and squalene levels.

\section{Animals Preparation and Treatment}

This study was approved for Ethical Clearance No. 608KEP-UB from Animal and Care and Use Committee, Brawijaya University. About 40 male Wistar rats, age 2-3 months, weight 150-200 g, were adapted for 1 week and fed ad libitum with standard diet AIN-93M. After the adaptation period, rats were divided into 8 groups consisted of one normal group and seven hypercholesterolemic groups. Groups of hypercholesterolemic rats were given atherogenic diet whereas the group of normal rats was given standard diet AIN-93M (Table 1). Aterogenic diet was given for 14 days. After rats from hypercholesterolemic groups had reached blood total cholesterol level $\geq 200 \mathrm{mg} / \mathrm{dl}$, atherogenic diet was stopped and all groups of rats were fed according to each treatment group for 8 weeks. At week 8 , blood serum total cholesterol, HDL cholesterol, and LDL cholesterol of rats was analyzed photometrically by CHOD-PAP method (Cholesterol 
Oxidase-Phenol Aminophenazone) (Siedel et al., 1983). The ratio of total cholesterol/HDL cholesterol and LDL cholesterol/HDL cholesterol were analyzed as the indicator of risk factors of coronary heart disease.

Treatment groups consisted of normal group of rats fed with standard diet AIN-93M (K1), hypercholesterolemic rats fed with non enriched instant noodle (K2), hypercholesterolemic rats fed with non enriched bread (K3), hypercholesterolemic rats fed with non enriched biscuit (K4), hypercholesterolemic rats fed with USM enriched instant noodle (K5), hypercholesterolemic rats fed with USM enriched bread (K6), hypercholesterolemic rats fed with USM enriched biscuit (K7), and hypercholesterolemic rats fed with standard diet AIN-93M (K8). In the end of week-8, all rats were sacrificed and abdominal aorta from the heart to the liver was collected.

Table 1: Composition of standard diet AIN-93M and atherogenic diet.

\begin{tabular}{ccc}
\hline \multirow{2}{*}{ Ingredient } & \multicolumn{2}{c}{ Composition (g/kg Diet) } \\
\cline { 2 - 3 } & AIN-93M & Atherogenic Diet \\
\hline Corn starch & 620.692 & 620.692 \\
casein & 140 & 116.528 \\
Sucrose & 100 & 100 \\
Soy bean oil & 40 & 40 \\
CMC & 50 & 50 \\
Mineral mix & 35 & 35 \\
Vitamin mix & 10 & 10 \\
L-cystin & 1.8 & 1.8 \\
Choline bitartrate & 2.5 & 2.5 \\
TBHQ & - & - \\
Cholic Acid & - & 2 \\
Cholesterol & - & 20 \\
Tallow & - & 185 \\
\hline
\end{tabular}

Source: Reeves et al. (1993).

\section{Aorta Histopathology Analysis}

Aorta samples were prepared according to the method of Thent et al. (2012). Embedding samples were performed on paraffin wax with tissue embedding center (Tissue-Tek TEC 5, Sakura, Japan). Aorta was cut in $5 \mu \mathrm{m}$ thickness of with 3 replications for each rats using microtome (LEICA RM2245). Samples were stained with Haematoxylin and Eosin (H\&E) (Tissue-Tek DRS 2000, Sakura, Japan) and then analyzed under the microscope (Olympus XC 10, Tokyo, Japan) with 400x enlargement. The histopathology image was analyzed using software OlyVIA 2.2. Intimae media thicknesses (IMT) was measured with dotSlide virtual microscopy system in four different section $\left(0^{\circ}, 90^{\circ}, 180^{\circ}, 270^{\circ}\right)$.

\section{Analysis of Bioactive Compounds}

Phytosterols analysis was followed method of Khatoon et al. (2010), vitamin E analysis was according to Ball (1988), and squalene analysis was using GC MS (GCMS-QP2010S Shimadzu) with derivatization method according to Mendez et al. (2003).

\section{Data Analysis}

Data were analyzed for variance test (ANOVA) and further tested by Duncan Multiple Range Test (DMRT) using software SPSS.

\section{RESULT AND DISCUSSION}

\section{Bioactive Compounds}

Table 2 showed all food products contained bioactive compounds from USM. Predominant bioactive compound in USM was phytosterols. The level of squalene was higher than vitamin E in USM (data not shown). Among food products there was different bioactive content. The highest amount of phytosterols and squalene was found in biscuit. Meanwhile, the highest quantity of vitamin $\mathrm{E}$ was in instant noodle. Bread showed the lowest bioactive compounds among all foods. All vitamin E in all food products is tocotrienols and no tocopherols was detected.

Table 2: Bioactive compounds of USM enriched food products

\begin{tabular}{|c|c|c|c|}
\hline \multirow{2}{*}{$\begin{array}{c}\text { Bioactive Compound } \\
(\mathrm{mg} / 100 \mathrm{~g})\end{array}$} & \multicolumn{3}{|c|}{ Product } \\
\hline & Biscuit & Instant Noodle & Bread \\
\hline $\begin{array}{l}\text { Total vitamin } \mathrm{E} \\
\text { (tocotrienols) }\end{array}$ & $23.46 \pm 0.71$ & $35.76 \pm 1.09$ & $22.68 \pm 0.05$ \\
\hline Total phytosterols & $261.35 \pm 5.01$ & $186.43 \pm 3.71$ & $122.11 \pm 2.59$ \\
\hline Squalene & $128.45 \pm 2.26$ & $72.51 \pm 1.42$ & $56.29 \pm 1.25$ \\
\hline
\end{tabular}

\section{Total Cholesterol Level}

Table 3 showed blood serum total cholesterol level after 8 week feeding. The lowest total cholesterol was found in normal group and the highest was hypercholesterolemia group, both were fed by standard diet. Group of rats treated by USM enriched products showed lower total cholesterol level than their corresponding food. It means that USM enriched food products decreased total cholesterol. The highest decrease was found in USM enriched bread compared to non-enriched. Compared to hypercholesterolemia group fed by standard diet, all hypercholesterolemia group fed by non-enriched biscuit, bread, and instant noodle showed lower total cholesterol level.

Ratio of total cholesterol to HDL cholesterol and LDL cholesterol to HDL cholesterol were indicators of the risk of coronary vascular diseases (CVD) (Fernandez and Webb, 2008). Hypercholesterolemic group which fed by standard diet showed the highest ratio, meanwhile the normal group fed by standard diet revealed the lowest. All food products caused decrease in the ratio although without enrichment of USM. Compared to non-enriched foods, all enriched foods showed better ratio of total cholesterol to HDL cholesterol and LDL cholesterol to HDL cholesterol. This is an indicator that enrichment of foods by USM improved lipid profile and lower the risk of CVD. Among all USM enriched foods, bread had the best ratio although the level of bioactive compounds in bread was the lowest.

\section{Aorta Histopathology}

Atherogenic diet was given for 14 days to raise blood cholesterol levels in hypercholesterolemic groups. Beside raising blood cholesterol levels, atherogenic diet also affected aortic histopathology. The normal group of rats (K1) showed a normal shape of the aorta with none foam cells, none visible fat accumulation or vacuolization in intima media layer, and none development of aortic plaque (Figure 1). 


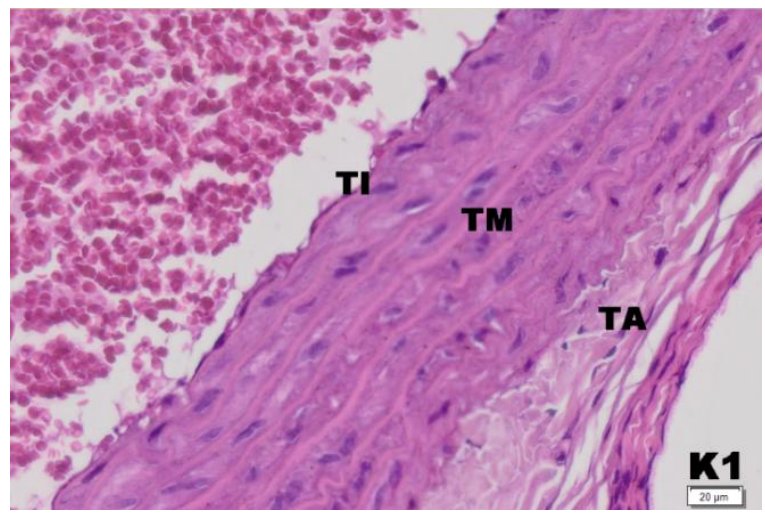

Fig. 1: Aortic histophatological image of normal group of rats + AIN-93M (K1) showing normal tunica intimae (TI), tunica media (TM), and tunica adventitia (TA) (enlargement: 400x, scale bar: $20 \mu \mathrm{m}$ ).

A group of hypercholesterolemic rats fed with standard diet (K8) showed a different result. There were irregular tunica intimae with a development of plaque and foam cells. Some fat deposits and dense irregular nuclei were found in tunica media. The elastic fibers were wavy and interrupted (Figure 8). Atherosclerosis is caused by elevated blood cholesterol levels especially low-density lipoprotein (LDL) cholesterol and the appearance of free radicals; reactive oxygen species (ROS); reactive nitrogen species (RNS) (Niki, 2011).

This group (K8) also revealed high level of LDL cholesterol and low level of HDL cholesterol (Table 3). Also, the ratio of total cholesterol to HDL cholesterol and LDL cholesterol to HDL cholesterol was the highest. Both ratio was an indicator of the risk of coronary vascular disease that usually initiated by aortic plague formation. High level of total cholesterol, LDL cholesterol, and low level of HDL cholesterol were probably as the cause of plague development in aorta of this group.

Rats fed with USM enriched food products showed better aortic histopathological image than non-enriched foods. USM enriched food groups had less fat deposit in tunica media, elastic fibers were straight and less wavy, foam cell also only found in USM enriched bread group (Figure 5, 6, 7). While non-enriched foods groups showed more fat deposit in tunica media, more foam cells in tunica intimae, elastic fibers were wavy and slightly interrupted (Figure 2, 3, 4). Rats fed with USM enriched food products had less severe morphological lesion and the aortic looked similar with normal group.
Profile lipid has main role in atherosclerosis development. In the end of week 8, profile lipid of rats fed with USM enriched food products was better than that of non-enriched food products. Nevertheless, rats fed with USM enriched food products had better profile lipid than non-enriched food products, as well as lower ratio of total cholesterol to HDL cholesterol and ratio of LDL cholesterol to HDL cholesterol (Table 3). Better aortic histopathology possibly was related to better profile lipid improvement in rats fed with USM enriched food products. The best ratio of total cholesterol to HDL cholesterol and LDL cholesterol to HDL cholesterol was found in group of rats fed by USM enriched bread. However, among USM enriched foods, the histopathological analysis revealed that the best therapeutic effect was found in USM enriched biscuit and the worst was in USM enriched bread. It seemed that in this case, the ratio of total cholesterol to HDL cholesterol and LDL cholesterol to HDL cholesterol not the only indicator for the aortic plaque development. Food intake also affected the therapeutic effect of USM enriched foods. Among USM enriched foods, intake of bread was the lowest (data not shown) that meant the intake of the bioactive compounds from bread also the lowest. Moreover, bread also showed the lowest fat content (data not shown) among USM enriched food products. Presumably, less fat intake resulted in better lipid profile and cholesterol ratio.

Previous research reported USM of PFAD contained bioactive compounds such as vitamin $\mathrm{E}$ (tocopherol and tocotrienols), phytosterols, and squalene (Estiasih et al., 2014; Ahmadi et al., 2012). Table 2 showed that all USM enriched food contained tocotrienols, phytosterols, and squalene. Bioactive compounds in USM presumed had a protective effect on aorta wall from radical damage and inhibited lipid oxidation. Aortic histopathological image of rats fed with USM enriched biscuit (K7) and instant noodle (K5) were slightly better than rats fed with USM enriched bread (K6) (Figure 5, 6, 7). USM enriched biscuit had the highest bioactive compounds and USM enriched bread had the lowest bioactive compounds (Table 2). The amount of bioactive compounds was assumed to be the cause of different therapeutic effect among USM enriched foods against atherosclerosis development. However, the existence of bioactive compounds in USM enriched food products, surely gave significant impact on prevention of atherosclerosis development compare with non-enriched food products.

Table 3: Total cholesterol level of group of rats after 8-week feeding.

\begin{tabular}{|c|c|c|c|c|c|}
\hline Group & $\begin{array}{c}\text { Total } \\
\text { Cholesterol } \\
\text { (mg/dl) }\end{array}$ & $\begin{array}{c}\text { LDL } \\
\text { Cholesterol } \\
(\mathbf{m g} / \mathbf{d l})\end{array}$ & $\begin{array}{c}\text { HDL } \\
\text { Cholesterol } \\
\text { (mg/dl) }\end{array}$ & $\begin{array}{c}\text { Total } \\
\text { Cholesterol/ } \\
\text { HDL } \\
\text { Cholesterol }\end{array}$ & $\begin{array}{c}\text { LDL } \\
\text { Cholesterol/ } \\
\text { HDL } \\
\text { Cholesterol }\end{array}$ \\
\hline K1 = Normal Group, Standard Diet & $95.21 \pm 3.17 \mathrm{a}$ & $29.89 \pm 3.50 \quad \mathrm{a}$ & $79.56 \pm 2.51 \mathrm{f}$ & $1.20 \pm 0.00 \mathrm{~h}$ & $0.37 \pm 0.03 \mathrm{~g}$ \\
\hline K2 = Hyphercholesterolemia Group, Instant Noodle & $142.11 \pm 8.05 \mathrm{e}$ & $44.66 \pm 2.01 \mathrm{~d}$ & $53.20 \pm 3.62 \mathrm{~b}$ & $2.67 \pm 0.03 \mathrm{~b}$ & $0.84 \pm 0.02 \mathrm{~b}$ \\
\hline K3 = Hypercholesterolemia Group, Bread & $125.78 \pm 6.69 \mathrm{~d}$ & $37.09 \pm 1.43 \mathrm{bc}$ & $60.44 \pm 2.62 \mathrm{c}$ & $2.08 \pm 0.02 \mathrm{e}$ & $0.61 \pm 0.00 \mathrm{~d}$ \\
\hline K4 = Hypercholesterolemia Group, Biscuit & $126.61 \pm 3.76 \mathrm{~d}$ & $39.30 \pm 1.65 \mathrm{bc}$ & $55.00 \pm 2.51 \mathrm{~b}$ & $2.30 \pm 0.04 \mathrm{~d}$ & $0.71 \pm 0.00 \mathrm{c}$ \\
\hline K5 = Hypercholesterolemia Group, USM Enriched Instant Noodle & $127.77 \pm 4.94 \mathrm{~d}$ & $38.33 \pm 1.80 \mathrm{bc}$ & $53.23 \pm 1.76 \mathrm{~b}$ & $2.40 \pm 0.01 \mathrm{c}$ & $0.72 \pm 0.01 \mathrm{c}$ \\
\hline K6 = Hypercholesterolemia Group, USM Enriched Bread & $102.31 \pm 4.02 \mathrm{~b}$ & $31.83 \pm 1.89$ a & $73.82 \pm 1.69 \mathrm{e}$ & $1.39 \pm 0.02 \mathrm{~g}$ & $0.43 \pm 0.02 \mathrm{f}$ \\
\hline K7 = Hypercholesterolemia Group, USM Enriched Biscuit & $108.93 \pm 4.46 \mathrm{c}$ & $36.12 \pm 1.33 \mathrm{~b}$ & $68.67 \pm 1.98 \mathrm{~d}$ & $1.63 \pm 0.07 \mathrm{f}$ & $0.53 \pm 0.00 \mathrm{e}$ \\
\hline K8 = Hypercholesterolemia Group, Standard Diet & $202.98 \pm 1.99 \mathrm{f}$ & $77.64 \pm 2.21 \mathrm{e}$ & $25.00 \pm 2.32 \mathrm{a}$ & $8.18 \pm 0.68 \mathrm{a}$ & $3.12 \pm 0.20 \mathrm{a}$ \\
\hline
\end{tabular}




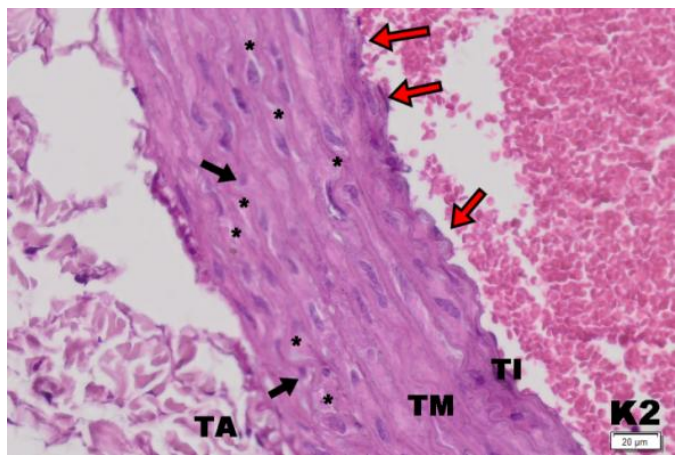

Fig. 2: Aortic histophatological image of hypercholesterolemic rats + instant noodle (K2) revealing irregular tunica intimae (TI) with foam cells (red arrows), irregular tunica media (TM) with fat deposits (stars) and dense irregular nuclei (black arrow), (enlargement: 400x, scale bar: $20 \mu \mathrm{m})$.

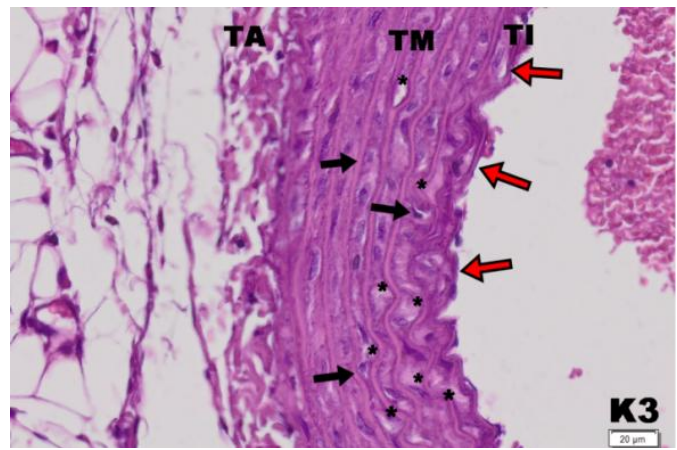

Fig. 3. Aortic histophatological image of hypercholesterolemic rats + bread (K3) showing irregular tunica intimae (TI) with more foam cells (red arrows), irregular tunica media (TM) with more fat deposits (stars), and dense irregular nuclei (black arrows) (enlargement: 400x, scale bar: $20 \mu \mathrm{m}$ ).

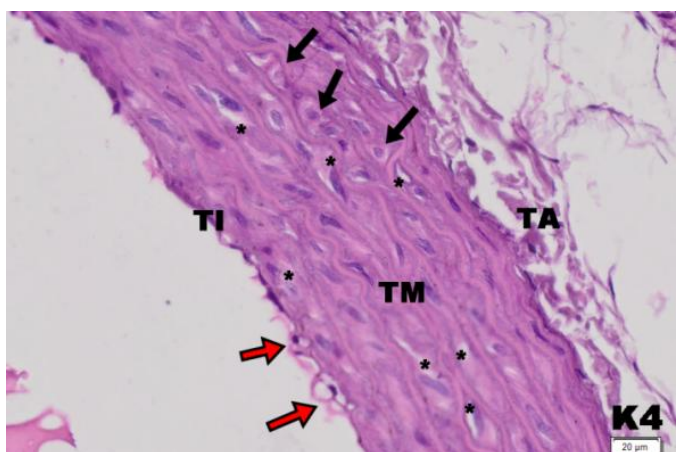

Fig. 4: Aortic histophatological image of hypercholesterolemic rats + biscuit (K4) revealing irregular tunica intimae (TI) with foam cells (red arrows), irregular tunica media (TM) with fat deposits (stars) and dense irregular nuclei (black arrows) (enlargement: 400x, scale bar: $20 \mu \mathrm{m}$ ).

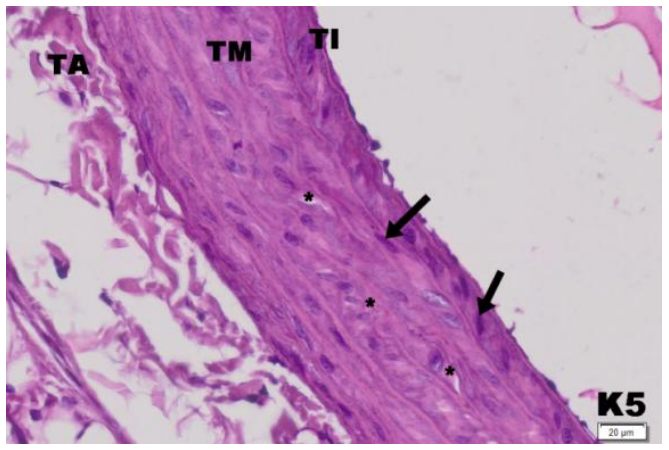

Fig. 5: Aortic histophatological image of hypercholesterolemic rats + USM enriched instant noodle (K5) illustrating straight tunica intimae (TI), less fat deposits in tunica media (TM), and elongated nuclei (black arrow) (enlargement: 400x, scale bar: $20 \mu \mathrm{m}$ ).

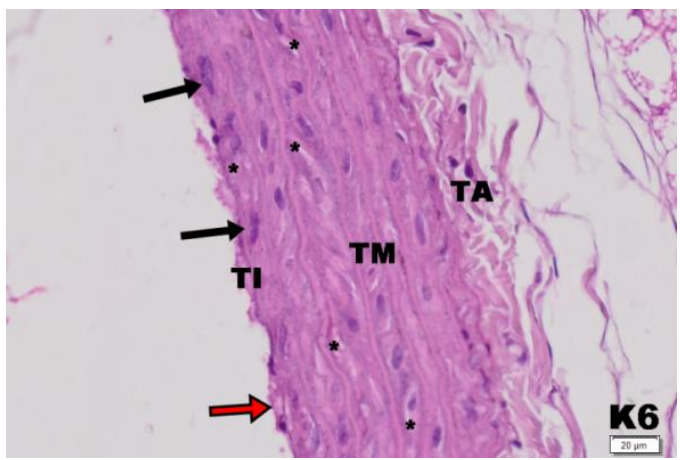

Fig. 6: Aortic histophatological image of hypercholesterolemic rats + USM enriched bread (K6) showing less severe morphological lesions of aortic wall, less foam cells (red arrow), less fat deposits (stars) in tunica media (TM), and elongated nuclei (black arrows) (enlargement: 400x, scale bar: $20 \mu \mathrm{m}$ ).

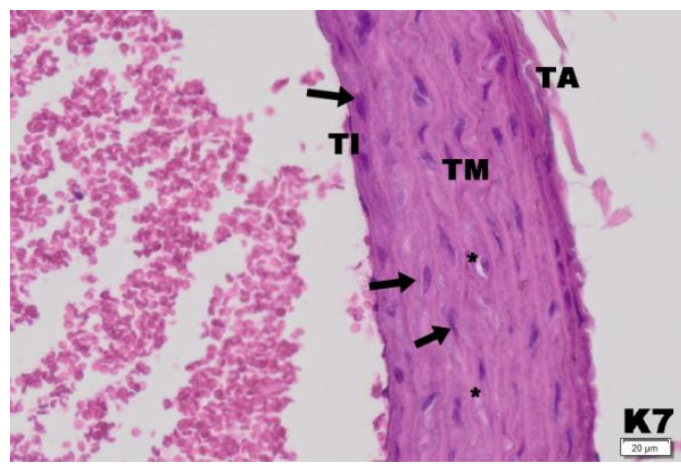

Fig. 7: Aortic histophatological image of hypercholesterolemic rats + USM enriched biscuit (K7) revealing straight tunica intimae (TI), less fat deposits (stars) in tunica media (TM), and elongated nuclei (black arrow) (enlargement: 400x, scale bar: $20 \mu \mathrm{m})$.

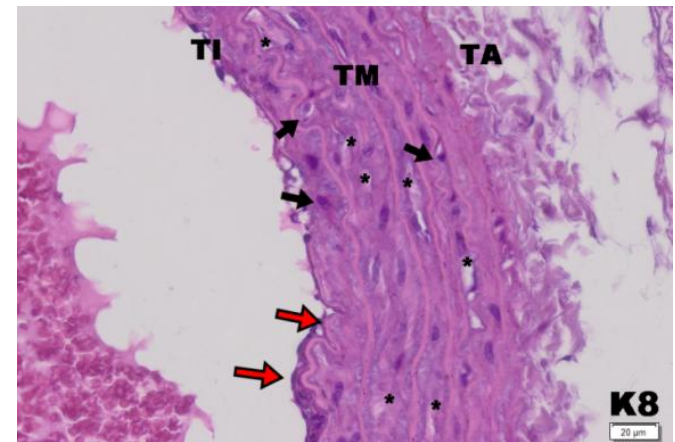

Fig. 8: Aortic histophatological image of hypercholesterolemic rats + standard diet AIN-93M (K8) showing irregular tunica intimae (TI) with foam cells and plaque development (red arrows), irregular tunica media (TM) with fat deposits (stars) and dense irregular nuclei (black arrows), (enlargement: 400x, scale bar: $20 \mu \mathrm{m})$.

Vitamin E as antioxidant has the ability to decrease the level of oxidized LDL and expression of CD38 which had a role in foam cell formation (Tang et al., 2014). The present study showed rats fed with USM enriched food products had none foam cells except group fed with USM enriched bread, which contained the lowest amount of vitamin E. Vitamin E also can decrease homocysteine in the blood and prevent the proliferation of smooth muscle cells (SMC) (Kirac et al., 2013). High level of 
homocysteine and cholesterol in blood will increase proliferation of SMC and oxidative stress which induced atherosclerosis (Ozer et al., 2003). Supplementation of vitamin $\mathrm{E}$ in rats increased expression of peroxisome proliferator activated receptor gamma (PPAR $\gamma)$, liver-x-receptor- $\alpha(\mathrm{LXR} \alpha)$, and ATP-binding cassette transporter ABCA1. Increased PPAR $\gamma$ gene expression stimulated $\mathrm{LXR} \alpha$ activation. PPAR $\gamma$ and LXR $\alpha$ stimulated more of ABCA1 gene expression. ABCA1 removed cholesterol from macrophage and preventing the appearance of foam cell (Tang et al., 2014). In this study, tocotrienols were the most responsible in preventing LDL oxidation since no tocopherols was detected in all food products. The addition of USM to instant noodle, bread, and biscuit also enriched the food products with phytosterols and squalene. Squalene as the antioxidant, protected cell membrane lipid bilayer from free radical damage (Farvin et al., 2007). Rats fed with high cholesterol diet and phytosterols had lower blood serum cholesterol levels, less damage in arterial walls, lower lipid accumulation in arterial walls, and less macrophages appearance on the arterial walls compared to control group (Bombo et al., 2013). The human study had shown that phytosterols increased circulation of endothelial progenitor cells (EPCs) that have a function for regeneration and protection of endothelial cells to prevent atherosclerosis (Chen et al., 2015). In this study, groups of rats fed with USM enriched foods had less fat deposits in the aortic wall and less endothelial lesion.

Vitamin E, phytosterols, and squalene as bioactive compounds in USM inhibited atherosclerosis development. Aortic histopathology image of hypercholesterolemic rats fed with USM enriched food products was the proof of its therapeutic effect. Hypercholesterolemic rats fed with non-enriched food products showed less improvement in histopathologic alterations. The damage of aortic in these groups was almost same with hypercholesterolemic rats those were fed by the standard diet. In the other side, hypercholesterolemic rats fed with USM enriched food product had less aortic damage and almost had a similar histopathological image with normal rats.

\section{Intimae Media Thickness (IMT)}

The present study revealed atherogenic diet treatment for 14 days increased blood total cholesterol levels but not sufficient to induce thickening of aortic wall. Some groups of hypercholesterolemic rats had lower average of IMT than normal group (Figure 9). Hypercholesterolemic rats fed with USM enriched biscuit had the highest IMT of all, but histopathological image showed this group had less aortic damage than other hypercholesterolemic groups. Average IMT of the normal group also did not significantly different with hypercholesterolemic rats fed the standard diet. Nevertheless, the histophatological image of hypercholesterolemic rats fed with standard diet showed aortic damage and started the atherosclerosis development.

Variation of intimae media thickness is caused by myoelectric (smooth muscle cells) structure and density of aortic layers with $18 \%$ degree of variation (Davis et al., 2010).
Atherogenic diet treatment for a longer time may need to induce aortic wall thickening in hypercholesterolemic rats.

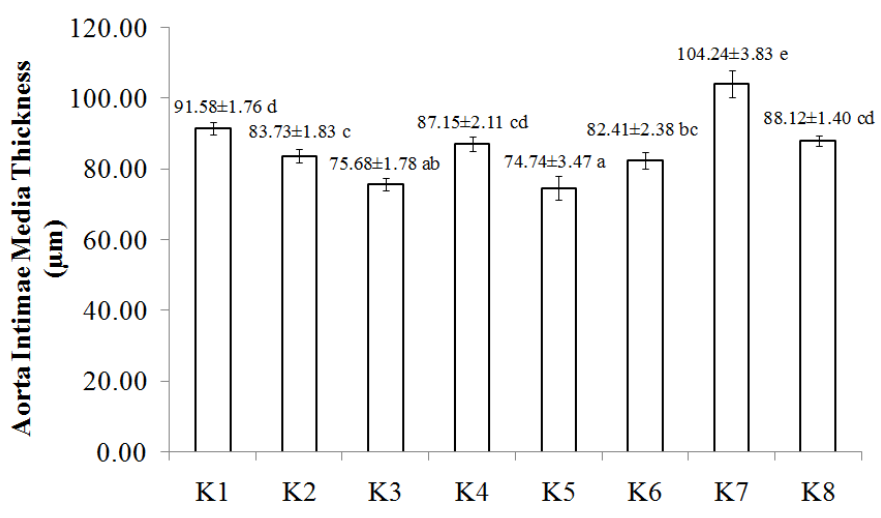

Fig. 9: Aorta intimae media thickness (IMT) at week $8 . \mathrm{K} 1=$ normal group, standard diet AIN-93M; K2=hyphercholesterolemia, instant noodle; $\mathrm{K} 3=$ =hypercholesterolemic, bread; $\mathrm{K} 4=$ hypercholesterolemic, biscuit; K5=hypercholesterolemic, USM enriched instant noodle; K6=hypercholesterolemic, USM enriched bread; K7=hypercholesterolemic, USM enriched biscuit, K8=hypercholesterolemic, standard diet AIN-93M.

\section{CONCLUSION}

USM enriched instant noodle, bread, and biscuit inhibited atherosclerosis plaque development in hypercholesterolemic rats. Bioactive compounds in USM of PFAD decreased foam cells development, decreased fat deposits, and improved morphological image of the aortic wall in hypercholesterolemic rats. Groups of hypercholesterolemic rats fed with USM enriched food products had a better aortic histopathological image than non-enriched food products. Between the USM enriched foods group, rats fed with USM enriched biscuit and instant noodle had better histophatological image than USM enriched bread. The best therapeutic effect was found in group of rats fed with USM enriched biscuit. However, overall rats fed with USM enriched food products had less severe aortic lesion than non-enriched foods and almost had a similar aortic histopathological image with the normal group of rats.

Treatment with atherogenic diet for 14 days could not induced atherosclerosis plaque in hypercholesterolemic groups of rats. The aortic IMT was not significantly different between the normal group of rats with the hypercholesterolemic group of rats. Longer time of atherogenic diet feeding may need to induce plaque development.

\section{ACKNOLEGMENT}

Financial support and sponsorship: The authors would like to thank and appreciate Directorate of Research and Community Service, Directorate General of Strengthening Research and Development, Ministry of Research, Technology, and Higher Education, for funding this research through Penelitian Strategis Nasional with Contract No. 007/SP2H/LT/DRPM/II/2016, February 17, 2016. 
Conflict of Interests: There are no conflicts of interest.

\section{REFERENCES}

Ahmadi K, Kumalaningsih S, Wijana S, Santoso I. Optimizing vitamin $\mathrm{E}$ purification from unsaponifiable matter of palm fatty acid distillate by low temperature solvent crystallization. Journal of Food Science and Engineering, 2012; 2: 557-563.

Awaisheh SS, Khalifeh MS, Al-Ruwaili MA, Khalil OM, AlAmeri $\mathrm{OH}, \mathrm{Al}-\mathrm{Groom} \mathrm{R}$. Effect of supplementation of probiotics and phytosterols alone or in combination on serum and hepatic lipid profiles and thyroid hormones of hypercholesterolemic Rats. Journal of Dairy Science, 2013; 96: 9-15.

Ball GFM. Fat-Soluble Vitamin Assays in Food Analysis (A Comprehensive Review). Elsivier Applied Science, 1988, London.

Bhanger MI, Iqbal S, Anwar F, Imran M, Akhtar M, Zia-ul-Haq M. Antioxidant potential of rice bran extracts and its effects on stabilisation of cookies under ambient storage. International of Food Science \& Technology, 2008; 43: 779-786.

Bombo RP, Afonso MS, Machado RM, Lavrador MS, Nunes VS, Quintao ER, Koike M, Catanozi S, Lin CJ, Nakandakare ER, Lottenberg AM. Dietary phytosterol does not accumulate in the arterial wall and prevents atherosclerosis of LDLr-KO mice. Atherosclerosis, 2013; 231(2): 442-447.

Buddhan S, Sivakumar R, Dhandapani N, Ganesan B, Anandan $R$. Protective effect of dietary squalene supplementation on mitochondrial fuction in liver of aged rats. Prostaglandins Leukot Essent Fatty Acids, 2007; 76(6): 349-355.

Che ICA, Karupaiah T, Sundram K, Tan YA, Balasundram N, Leow SS, Nasruddin NS, Sambanthamurthi R. Oil palm phenolics and vitamin $\mathrm{E}$ reduce atherosclerosis in rabbits. Journal of Functional Foods, 2014; 7(1): 541-550.

Chen D, Huang P, Chiang C, Leu H, Chen J, Lin S. Phytosterol increase circulating endothelial progenitor cells and insulin-like growth factor-1 levels in patients with nonalcaholic fatty liver disease: A randomized crossover study. Journal of Functional Foods, 2015; 13:148157.

Davis PH, Dawson JD, Blecha MB, Mastbergen RK, Sonka M. Measurement of aortic intimal-medial thickness in adolescents and young adults. Ultrasound Med Biol, 2010; 36(4): 560-565.

Estiasih T, Ahmadi K, Widyaningsih TD, Maligan JM, Mubarok AZ, Zubaidah E, Mukhlisiyyah J, Puspitasari R. Bioactive compounds of palm fatty acid distillate (PFAD) from several palm oil refineries. Journal of Food Science and Technology, 2013; 5(9): 1153-59.

Estiasih T, Ahmadi K, Widyaningsih TD, Rhitmayanti E, Fidyasari A, Purnomo K, Wahyuni Y. The effect of unsaponifiable fraction from palm fatty acid distillate on lipid profile of hypercholesterolemic rats. Journal of Food and Nutrition Research, 2014; 2(12): 1029-1036.

Farvin, KHS, Anandan R, Kumar SHS, Shiny KS, Mathew S, Sankar TV, Nair PGV. Cardio protective effect of squalene on lipid profile in isoprenaline-induced myocardial infarction in rats. J.Med.Food, 2006; 9(4): 531-536.

Fernandez ML, West KL. Mechanisms by which dietary fatty acids modulate plasma lipids. J Nutr, 2005; 135(9): 2075-2078.

Fernandez ML, Webb D. The LDL to HDL Cholesterol Ratio as a Valuable Tool to Evaluate Coronary Heart Disease Risk. J Am Coll Nutr, 2008, 27(1): 1-5.

Guillen N, Acin S, Navarro MA, Perona JS, Arbones-Mainar JM, Arnal C, Sarria AJ, Surra JC, Carnicer R, Orman I, Segovia JC, RuizGutierrez V, Osada J. Squalene in a sex-dependent manner modulates atherosclerotic lesion which correlates with hepatic fat content in apoEknockout male mice. Atherosclerosis, 2008; 197(1): 72-83.

Hasty AH, Gruen ML, Terry ES, Surmi BK, Atkinson RD, Gao L, Morrow JD. Effects of vitamin E on oxidative stress and atherosklerosis in an obese hyperlipidemic mouse model. J Nutr Biochem, 2007; 18(2): 127-133.
Hayes K, Pronczuk A, Perlman D. Vitamin E in enriched cow milk uniquely enriches human plasma lipoproteins. Am J Clin Nutr, 2001; 74(2): 211-218.

Jew S, AbuMweis SS, Jones PJ. Evolution of the human diet: linking our ancestral diet to modern functional foods as a means of chronic disease prevention. J Med Food, 2009; 12(5): 925-934.

Khatoon S, Rajan, RGR, Krishna AGG. Physicochemical characteristics and composition of Indian soybean oil deodorizer distillate and the recovery of phytosterols. J. Am Oil Chem Soc, 2010, 87(3): 321326.

Kirac D, Negis Y, Ozer NK. Vitamin E attenuates homocystein and cholesterol induced damage in rat aorta. Cardiovasc Pathol, 2013; 22(6): 465-472.

Loganathan R, Selvaduray KR, Radhakrishnan A, Nesaretnam K. Palm oil: rich in health promoting phytonutrients. Palm Oil Developments, 2009; 50: 16-25.

Martinez CS, Ribotta PD, Anon MC, Leon AE. Effect of amaranth flour (Amaranthus mantegazzianus) on the technological and sensory quality of bread wheat pasta. Food Sci Technol Int, 2014; 20(2):127-135.

Mendez E, Blanco M, Laguna A, Garcia E. Isolation and characterization of a mixture of higher primary aliphatic alcohols of high molecular weight from henequen (Agave furcroydes L.) wax. Revista CENIC Ciencias Químicas, 2003, 34(1): 35-38

Mukherjee S, Mitra A. Health effects of palm oil. J Hum Ecol, 2009; 26(3): 197-203.

Nestel P, Cehun M, Pomeroy S, Abbey M, Weldon G. Cholesterol-lowering effects of plant sterol esters and non-esterified stanols in margarine, butter and low-fat foods. Eur J Clin Nutr, 2001; 55(12): 1084-1090

Niki E. Do free radicals play casual role in atherosclerosis? Low density lipoprotein oxidation and vitamin E revisited. J.Clin Biochem Nutr, 2011; 48(1): 3-7.

Ozer NK, Negis Y, Aytan N. Molecular mechanisms of cholesterol or homocysteine effect in the development of atherosclerosis: Role of vitamin E. BioFactors, 2003; 19(1-2): 63-70.

Qureshi AA, Sami SA, Salser WA, Khan FA. Dose-dependent suppression of serum cholesterol by tocotrienol-rich fraction (TRF25) of rice bran in hypercholesterolemic humans. Atherosclerosis, 2002; 161(2): 199-207.

Reeves PG, Nielson FH, Fahey GC Jr. AIN-93 purified diets for laboratory rodents: final report of The American Institute of Nutrition ad hoc Writing Committee on reformulation of the AIN-76A rodent diet. J Nutr, 1993; 123(11): 1939-1951.

Siedel J, Hagele EO, Ziegenhorn J, Wahiefeld AW. Reagent for the enzymatic determination of serum total cholesterol with improved lipolytic efficiency. Clin Chem, 1983, 29:1075-1080.

Tang F, Lu M, Zhang S, Mei M, Wang T, Liu P, Wang H. Vitamin E conditionally inhibits atherosclerosis in ApoE knockout mice by anti-oxidation and regulation of vasculature gene expressions. Lipids, 2014; 49(12): 1215-1223.

Thent ZC, Lin TS, Das S, Zakaria Z. Histological changes in the heart and the proximal aorta in experimental diabetic rats fed with piper sarmentsoum. Afr J Tradit Complement Altern Med, 2012; 9(3): 396-404.

Tomkin GH, Owen D. LDL as a cause of atherosclerosis. The Open Atherosclerosis \& Trombosis Journal, 2012; 5: 13-21.

van het Hof KH, Tijburg LB, de Boer HS, Wiseman SA, Weststrate JA. Antioxidant enriched margarine increases the antioxidant status. Eur J Clin Nutr, 1998; 52(4): 292-299.

\section{How to cite this article:}

Ahmadi K, Wulansari A, Subroto Y, Estiasih T. Protective Effect of Food Products Enriched with Unsaponifiable Matter from Palm Fatty Distillate on The Aorta of Hypercholesterolemic Rats. J App Pharm Sci, 2017; 7 (12): 090-096. 